\title{
DRUG UTILIZATION STUDY IN PAEDIATRICS OPD OF A TERTIARY CARE HOSPITAL: RECOMMENDATION FOR IMPLEMENTATION OF RATIONAL USE OF DRUGS
}

\author{
VARSHA SARGWAN ${ }^{\mathrm{a} 1}$ AND SANJAY KHATTRI ${ }^{\mathrm{b}}$

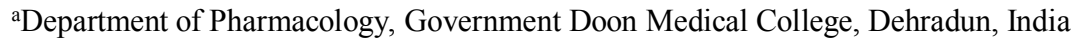 \\ bDepartment of Pharmacology and Therapeutics, King George's Medical University, Lucknow, U.P., India
}

\begin{abstract}
A drug utilization study is a study designed to describe-quantitatively and qualitatively-the population of users of a given drug (or class of drugs) and /or the conditions of use. Studies on the process of drug utilization focus on factors related to prescribing, dispensing, administering and taking of medication and its associated events. Drug utilization play a significant role in helping the health-care system to understand, interpret and improve the prescribing administration and use of medications. To determine drug utilisation pattern in outpatient departments in paediatrics OPD of King George's Medical University, Lucknow. This was an open label, prospective, cross-sectional, observational study conducted in Outpatient Department (OPD) of paediatrics. The sample size was kept 400 in department in accordance with the World Health Organization manual Study. Data was expressed as mean $\pm \mathrm{SD}$, frequency, range and percentages. No statistical hypothesis was tested. After compiling the data, overall review shows average number of drugs as 2 and standard deviation with \pm 1.1.Drugs by generic name as $1 \% .34 \%$ antibiotics prescribed and $22 \%$ drugs from essential drug list. According to the data, maximum number of drugs were two.Maximum percentage of drugs prescribed per prescription is two i.e., $49 \%$ and minimum is $1 \%$ with greater than four number of drugs in a prescription in paediatrics OPD. Data shows that antibiotic use is $23 \%$. Among antimicrobials fluoroquinolones were maximumly prescribed with $\mathbf{5 8 \%}$. Majority of the drugs prescribed were of different brands and not generic names. Large number of drugs are not from essential list of medicine.
\end{abstract}

KEYWORDS: Rational Drugs, Genericname, Cross Sectional Study

The prescription, marketing and use of drugs in a society, with reference to resulting medical, social and economic consequences is known as drug utilization research. (Patel et al., 2013) It holds an vital role in clinical practice as it forms the foundation for making amendments in the drug dispensing policies. The main aim of such research is to facilitate rational drug use. As it helps in developing strategies to utilize health resources in the most fruitful manner, it is needed in a developing economy like India (Mittal et al., 2014).

Now, a number of different terms have come into use and it is crucial to understand the interrelationships of the different domain. These type of studies are important for gaining data about the patterns and quality of use, the determinants of drug use, and the outcomes of use. The WHO drug use indicators are standardized and are recommended for inclusion in effective and fruitful drug utilization studies (WHO, 2003).

Nowadays, drug utilization is the main focus of numerous economical and medical debates in a large number of countries including India (Zivković et al., 200609). The prescriptions containing emergency drugs for emergency department and indoor patient clinics were excluded from the study (Guillot et al., 2014).Over antibiotic use even when not required is the main culprit to develop resistance to antibiotics (Muller et al., 2006). Drug utilization studies are informative and powerful tool to ascertain the role of drugs in society (Veettil et al., 2014). The indicators are standardised and used potentially to target problems in drug use and priortise needs for those problems (WHO, 1993). This study mainly aims to describe the prescribing pattern and drug utilization with the WHO core prescribing indicators in Outpatient Department of paediatrics (Jadhav et al., 2013).

\section{MATERIAL AND METHODS}

Study Site

Outpatient Department of Paediatrics of King George's Medical University, Lucknow.

\section{Study Design}

Study is designed to be an observational crosssectional study.

\section{Study Subject}

Patients registered in the OPD of paediatrics, King George's Medical University, Lucknow will be randomly selected. 
This was an open label, prospective, crosssectional, observational study conducted in Outpatient Department (OPD) of paediatrics. The sample size was kept 400 in the department in accordance with the World Health Organization manual.

Data were analyzed for; total number of drugs prescribed per patient; the total number of antimicrobials used per patient; use of generic and brand drugs etc.

\section{Statistical Analysis}

Data was expressed as mean $\pm \mathrm{SD}$, frequency, range and percentages. No statistical hypothesis was tested.

\section{Observation}

In this study four hundred prescriptions of the department $(n=400)$ were analyzed. During this study, the number of drugs per prescription varied from zero to four and the average number of drugs per prescription was 2 . Drugs were prescribed in different dosage forms.

Table 1: Details of drug utilization based on WHO/INRUD indicators in pediatrics OPD $n=400$.

\begin{tabular}{|l|c|}
\hline \multicolumn{1}{|c|}{ Indicators assessed } & $\begin{array}{c}\text { Data } \\
\text { value }\end{array}$ \\
\hline Average number of drugs per encounter & $2 \pm 1.1$ \\
\hline $\begin{array}{l}\text { Percentage of drugs prescribed by generic } \\
\text { name }\end{array}$ & $1 \%$ \\
\hline $\begin{array}{l}\text { Percentage of encounters with an antibiotic } \\
\text { prescribed }\end{array}$ & $34 \%$ \\
\hline $\begin{array}{l}\text { Percentage of encounters with an injection } \\
\text { prescribed }\end{array}$ & $12 \%$ \\
\hline $\begin{array}{l}\text { Percentage of drugs prescribed from national } \\
\text { essential drug list/formulary }\end{array}$ & $22 \%$ \\
\hline
\end{tabular}

Table $1 \&$ Figure 1 shows that average number of drugs given per counter was 2 which is quite less as prescribed in medicine and surgery OPD. This is because generally paediatrics department does not prescribe irrelevant or a number of drugs. $22 \%$ of drugs were prescribed from essential drug list which is very rational compared to others.

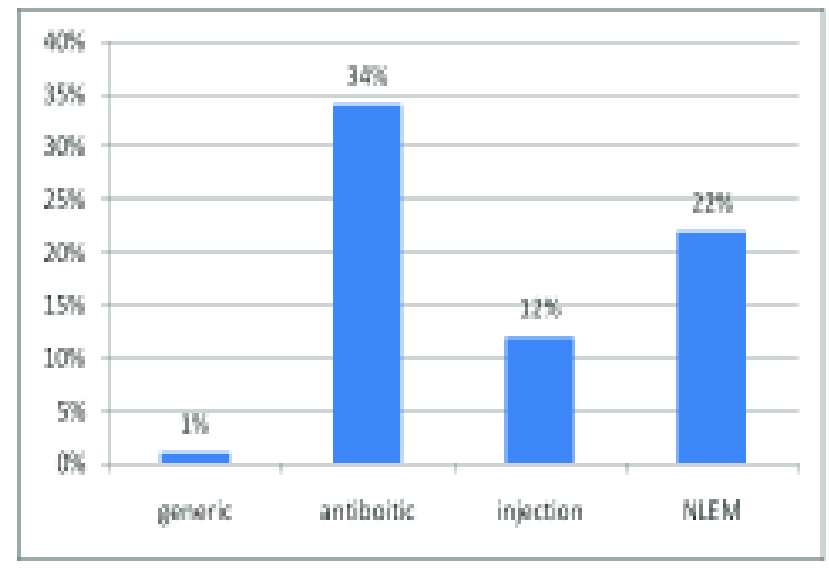

Figure 1: Details of drug utilization based on WHO/INRUD indicators in paediatrics OPD $n=400$

Table 2: No. of drug products prescribed in pediatrics OPD $n=400$

\begin{tabular}{|c|c|c|c|}
\hline $\begin{array}{c}\text { Sl. } \\
\text { No. }\end{array}$ & $\begin{array}{c}\text { No. of } \\
\text { drugs used }\end{array}$ & $\begin{array}{c}\text { Number } \\
\text { (out of 400) }\end{array}$ & Percentage \\
\hline 1 & Zero & 8 & $2 \%$ \\
\hline 2 & One & 184 & $46 \%$ \\
\hline 3 & Two & 196 & $49 \%$ \\
\hline 4 & Three & 8 & $2 \%$ \\
\hline 5 & $\geq$ four & 4 & $1 \%$ \\
\hline
\end{tabular}

Table $2 \&$ figure 2 depicts maximum use of two drugs per prescription.

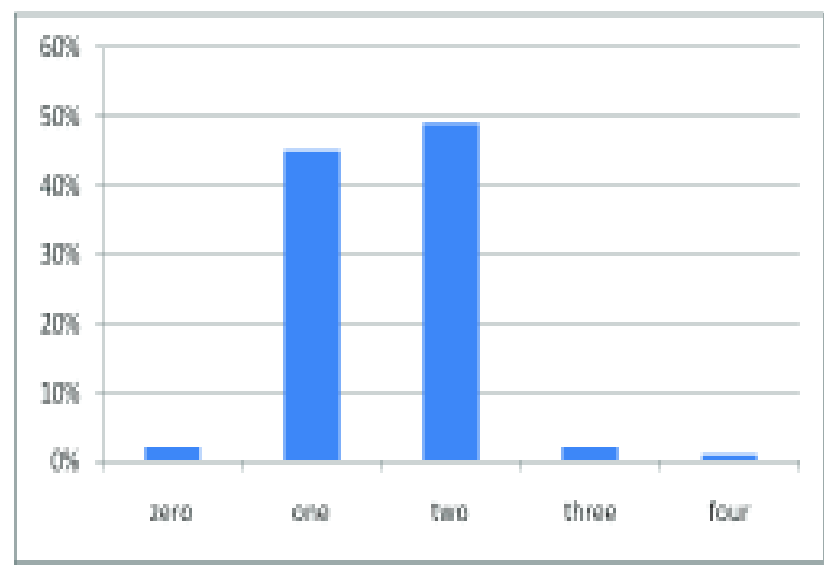

Figure 2: No of drug products prescribed in pediatrics OPD $n=400$ 
Table 3: Different types of drug products prescribed in pediatrics OPD $n=400$

\begin{tabular}{|c|c|c|c|}
\hline $\begin{array}{c}\text { Sr. } \\
\text { No. }\end{array}$ & Type & $\begin{array}{c}\text { Number } \\
\text { (Out of } \\
\text { 400) }\end{array}$ & Percentage \\
\hline 1 & Antibiotics & 93 & $23 \%$ \\
\hline 2 & Antiallergy & 33 & $8 \%$ \\
\hline 3 & Antacids\PPIs & 4 & $1 \%$ \\
\hline 4 & NSAIDs & 33 & $8 \%$ \\
\hline 5 & Decongestants & 49 & $12 \%$ \\
\hline 6 & Vitamins & 159 & $39 \%$ \\
\hline 7 & CNS Drugs & 16 & $4 \%$ \\
\hline 8 & Hormones & 9 & $2 \%$ \\
\hline 9 & $\begin{array}{c}\text { Antihypertensives } \\
\& \text { Other CVS drugs }\end{array}$ & 8 & $2 \%$ \\
\hline 10 & $\begin{array}{c}\text { Sedatives \& } \\
\text { Anxiolytics }\end{array}$ & 4 & $1 \%$ \\
\hline
\end{tabular}

Table $3 \&$ figure 3 shows that in paediatrics OPD maximum number of drug which is prescribed in prescriptions is antibiotics i.e., $23 \%$

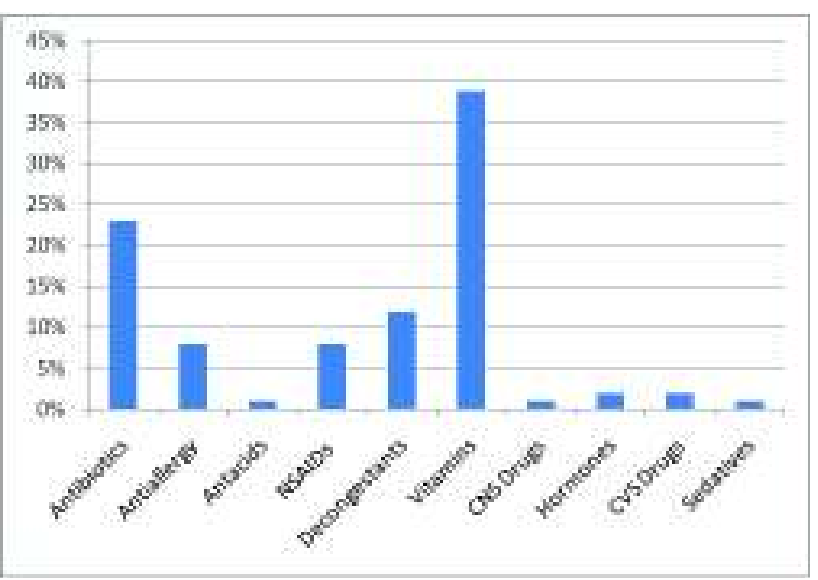

Figure 3: Different types of drug products prescribed in pediatrics OPD $n=400$

Table $4 \&$ figure 4 shows greater use of again fluoroquinolones with $58 \%$ and again minimum use of polypeptides with $1 \%$.
Table 4: Different types of drug products prescribed in pediatrics OPD $n=400$.

\begin{tabular}{|c|c|c|c|}
\hline $\begin{array}{c}\text { Sl. } \\
\text { No. }\end{array}$ & $\begin{array}{c}\text { Antimicrobial } \\
\text { Classes }\end{array}$ & $\begin{array}{c}\text { Number } \\
\text { (Out of } \\
\text { 400) }\end{array}$ & Percentage \\
\hline 1 & Fluoroquinolone & 232 & $58 \%$ \\
\hline 2 & Penicillin & 16 & $4 \%$ \\
\hline 3 & Tetracycline & 10 & $2 \%$ \\
\hline 4 & Chloramphenicol & 37 & $9 \%$ \\
\hline 5 & Macrolide & 417 & $4 \%$ \\
\hline 6 & Aminoglycoside & 88 & $22 \%$ \\
\hline 7 & $\begin{array}{c}\text { Polypeptides and } \\
\text { others }\end{array}$ & 4 & $1 \%$ \\
\hline
\end{tabular}

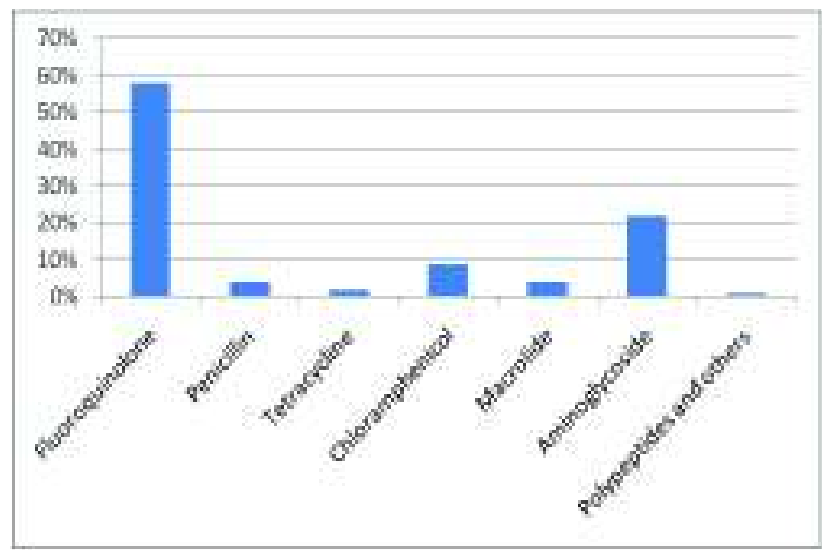

Figure 4: Different types of drug products prescribed in pediatrics OPD $n=400$

\section{CONCLUSION}

- Majority of the drugs prescribed were of different brands. This habit of practitioners needs to be changed.

- Large number of drugs are not from essential list of medicine.

- More than one antibiotics are prescribed to the patient which is not required for the treatment of that particular disease.

\section{DISCUSSION}

Drug utilization studies are vital for obtaining data about the patterns and quality of use, the determinants of drug use, and the outcomes of use. The WHO drug use indicators are highly standardized and are recommended for inclusion in drug utilization studies as these are helpful in 
the study (WHO, 2003). The present study aims mainly to describe the current prescribing pattern and drug utilization with the WHO core prescribing indicators in Outpatient Department.

Average number of drugs per prescription is an important index as it tends to measure the degree of polypharmacy (WHO). It gives scope for review and educational intervention in prescribing practices. In this study the average number of drugs per prescription was 2 .

The percentage of drugs prescribed by generic name was $1 \%$ which was quite low compared to other studies. Most of the drugs were prescribed by brand names in this study, which shows popularity of brands amongst the practitioners and the influence of pharmaceutical companies. They are reluctant to prescribe drugs by generic name because it may result in the purchase of drugs of variable potency and underpotent generic antibiotics which may contribute to drug resistance and variability in clinical response. However, prescribing drugs by generic name makes the treatment low cost and rational as it reduces prescription writing errors and confusion of dispensing of different brand names which sound alike and spell similar. (WHO)

Antibiotics were frequent and number of encounters with antibiotics was $23 \%$. The high and over use of antibiotics may reflect the severity of infections and low sanitation in the given region (Mittal et al., 2014).

Patient's knowledge of correct dosage schedule and duration ensures adherence to treatment compliance without indiscriminate use and promotes rational drug use. (WHO)

Antibiotics constituted $23 \%$ of the total drugs prescribed. Out of which $58 \%$ (232) were fluoroquinolones only and rest were prescribed as other antibiotics, nonsteroidal anti-inflammatory drugs (NSAID), and glucocorticoids.

Fluoroquinolones were the most common and casual group of antibiotics prescribed which were similar to reports of previous studies. The data have also exposed that there is a need for sentience and awareness programmes on rational prescribing of NSAIDs and other drugs towards optimal therapeutics and improved patient care in India (Paul and Chauhan, 2005). PPIs as becoming available over the counter (OTC), no studies have assessed the requirement of its use (Sheikh et. al.).

Irrational use of medicines is an extremely serious global problem that is harmful and need to be managed properly within time (WHO, 2011).

\section{REFERENCES}

Guillot J., Roy H., Ovetchkine P. and Bussières J.F., 2014. Usefulness of Defined Daily Dose and Days of Therapy in Pediatrics and Obstetrics-Gynecology: A Comparative Analysis of Antifungal Drugs. J. Pediatr Pharmacol Ther., 19(3): 196-201.

Jadhav P.R., Moghe V.V. and Deshmukh Y.A., 2013. Drug Utilization Study in Ophthalmology Outpatients at a Tertiary Care Teaching Hospital ISRN Pharmacol., 38(2):717-24.

Mittal N., Mittal R., Singh I., Shafiq N. and Malhotra S., 2014. Drug Utilisation Study in a Tertiary Care Center: Recommendations for Improving Hospital Drug Dispensing Policies. Indian J. Pharm. Sci., 76(4): 308-314.

Muller A., Monnet D.L., Talon D., Hénon T. and Bertrand X., 2006. Discrepancies between prescribed daily doses and WHO defined daily doses of antibacterials at a university hospital. Br. J. Clin. Pharmacol., 61(5): 585-591.

Patel M.K., Barvaliya M.J., Patel T.K. and Tripathi C.B., 2013. Drug utilization pattern in critical care unit in a tertiary care teaching hospital in India. Int. J. CritIllnInj Sci., 3(4): 250-255.

Paul A.D. and Chauhan C.K., 2005. Study of usage pattern of nonsteroidal anti-inflammatory drugs (NSAIDs) among different practice categories in Indian clinical setting European Journal of Clinical Pharmacology, 60(12): 889-892.

Sheikh I., Waghray A. and Waghray N., Dong Consumer use of over-the-counter proton pump inhibitors in patients with gastroesophageal reflux disease.

The World Medicines Situation 2011, Rational Use of Medicines, World Health Organization, 2011.

Veettil S.K., Rajiah K. and Kumar S., 2014. Study of Drug Utilization Pattern for Acute Exacerbation of 
SARGWAN AND KHATTRI: DRUG UTILIZATION STUDY IN PAEDIATRICS OPD OF A TERTIARY CARE HOSPITAL...

Chronic Obstructive Pulmonary Disease in Patients Attending a Government Hospital in Kerala, India. J. Family Med. Prim. Care, 3(3): $250-254$.

World Health Organization, Introduction to Drug Utilization Research, WHO, Oslo, Norway, http://apps.who.int/medicinedocs/ en/d/Js4876e/.

World Health Organization (WHO) International Working Group for Drug Statistics Methodology, WHO Collaborating Centre for Drug Statistics Methodology, WHO Collaborating Centre for Drug Utilization Research and Clinical
Pharmacological Services, Introduction to Drug Utilization Research, WHO, Oslo, Norway, 2003.

World Health Organization (WHO) and International Network for Rational Use of Drugs, How to Investigate Drug Use in Health Facilities: Selected Drug Use indicators, WHO/DAP/, WHO, Geneva, Switzerland, 1993.

Zivković K., Zelić-Kerep A., Stimac D., Ozić S. and Zivković N., A study on the quality of outpatient prescription of psychopharmaceuticals in the City of Zagreb 2006-2009. 